\title{
An OT Analysis of Neutral Tone of Luoshan Dialect*
}

\author{
XU Juan \\ Communication University of China, Beijing, China
}

\begin{abstract}
The paper studies the neutral tone of Luoshan Dialect. Neutral tone in disyllabic and trisyllabic sequences is firstly analyzed on the basis of acoustic experiment, and then a phonological analysis of the behavior of the neutral tone is carried out within the framework of Optimality Theory. The findings show that by employing three faithfulness constraints and three markedness constraints, the behavior of the neutral tone in Luoshan Dialect can been explicitly explained, indicating the strong explanatory power and universality of the OT theory.
\end{abstract}

Keywords: neutral tone, dialect, Optimality Theory

\section{Introduction}

Luoshan is a small county with long history and brilliant culture. Lying in south Henan Province, it covers an area about 3,000 square kilometers, with a constant population of about 200,000.

Few materials on the tones of Luoshan Dialect (LSD) have been found. The authorized book on dialects entitled Hanyu Fangyan yu Fangyan Diaocha (Chinese Dialects and Dialect Survey, ZHAN, 1991) only classifies Xinyang (where Luoshan county belongs to) dialect as one of the sub-dialects of Zhongyuan Mandarin-Xinbeng Group, with no more details given. A more comprehensive description of the phonetics of Luoshan dialect comes from The Record of Luoshan County (Luoshan Local Records Compiling Committee, 1987). While with a little basic linguistic knowledge one can find that the record is a little out-of-dated, perhaps because the book was compiled nearly 20 years ago, during which things changed and keep changing.

It is a pity that up to now no literature describing the neutral tone behavior in the dialect was found, and the above mentioned two are all that have been found in LSD.

\section{Acoustic Experiment on Neutral Tone in LSD}

\section{Tones of Citation Syllables}

Pitch values presented in the above literature are got mainly through aural perception. There is by no means a thorough and wide-range study on the tones in LSD, let alone using experimental methods. Adopting the methods of experimental phonetics and with the help of a speech analysis program, a detailed description of the tonal system of LSD is acquired based on acoustic data (see author's PCC 2008 paper for more details).

There are four citation tones in LSD, namely "yinping (yin even)", "yangping (yang even)", "shangsheng (low-dipping)", and "qusheng (departing)", which are referred to hereinafter as Tone 1 (T1), Tone 2 (T2), Tone 3 (T3), and Tone 4 (T4) respectively.

\footnotetext{
* Acknowledgements: This paper is one of the research results of a research project in Communication University of China: Study on the Historical Differentiation of Chinese Allotropy Words (CUC12C13), and is supported by China Scholarship Council. XU Juan, assistant professor, Ph.D., Faculty of Literature and Law, Communication University of China.
} 
Experiment results show that $\mathrm{T} 1$ is a high-falling tone. $\mathrm{T} 2$ in isolation is inherently a high convex tone, instead of a high-level as is reported in the Record (1987). T3 is a rising tone. While for T4, aurally it may appear as a simple low tone, which accords with my result with T4 in connected speech, but through acoustic experiment it is found that T4 in isolation is a low tone with inner concave. Pitch values and durations are shown in the Table 1.

Table 1

Duration and Pitch Value: Citation Tones

\begin{tabular}{|c|c|c|c|c|c|}
\hline \multicolumn{2}{|c|}{ Tone } & T1 & T2 & T3 & T4 \\
\hline \multirow{2}{*}{$\begin{array}{c}\text { Duration } \\
(\mathrm{ms})\end{array}$} & Male & 284 & 266 & 388 & 557 \\
\cline { 2 - 6 } & Female & 394 & 414 & 446 & 559 \\
\hline \multirow{2}{*}{ Pitch value } & Male & 42 & 454 & 35 & 323 \\
\cline { 2 - 6 } & Female & 32 & 454 & 35 & 323 \\
\hline Example & & $\begin{array}{c}{[\mathrm{k} ə]} \\
\text { "brother" }\end{array}$ & $\begin{array}{c}{[\mathrm{p} \text { 'a] }} \\
\text { "climb" }\end{array}$ & $\begin{array}{c}{[\mathrm{ta}]} \\
\text { "big" }\end{array}$ \\
\hline
\end{tabular}

\section{The Neutral Tone in LSD}

Sequences with neutral syllables in pattern $\mathrm{S}+\mathrm{N}$ (stressed tone + neutral tone) and $\mathrm{S}+\mathrm{N}+\mathrm{S}$ are recorded. The deliberate choice of the pattern is to discover the influence the stressed syllables have on the neutral ones in both preceding and following positions.

The neutral tone in disyllabic sequences. Pitch values and durations of the patter $\mathrm{S}+\mathrm{N}$ are presented as follows:

Table 2

Duration and Pitch Value: $T x+N$

\begin{tabular}{|c|c|c|c|c|c|c|}
\hline \hline \multicolumn{2}{|c|}{ Item } & Tone & $1+0$ & $2+0$ & $3+0$ & $4+0$ \\
\hline \multirow{3}{*}{ Duration (ms) } & \multirow{3}{*}{ Syllable } & $\mathrm{M}$ & $383+199$ & $490+176$ & $440+182$ & $404+325$ \\
\cline { 3 - 7 } & & $\mathrm{F}$ & $359+259$ & $385+238$ & $393+294$ & $349+337$ \\
\cline { 3 - 7 } & \multirow{2}{*}{ Tone } & $\mathrm{M}$ & $329+121$ & $337+128$ & $332+123$ & $336+247$ \\
\cline { 3 - 7 } & & $\mathrm{F}$ & $308+201$ & $302+182$ & $306+232$ & $290+264$ \\
\hline \multicolumn{2}{|c|}{ Pitch value } & $\mathrm{M}$ & $32+22$ & $43+32$ & $34+43$ & $32+22$ \\
\cline { 3 - 7 } & $\mathrm{F}$ & $42+22$ & $454+32$ & $34+43$ & $32+22$ \\
\hline
\end{tabular}

It can be easily seen from the above table that the duration of a neutral tone is shorter than that of the stressed one. This is a common phenomenon that has been proved in many dialects, of which the most noted one is the result in LIN and YAN (1980), which pointed out that the duration of a neutral tone is almost half of that of the stressed syllable in Putonghua. While in LSD the neutral tone is not as short as that. The average duration of the stressed syllables in LSD is about $382 \mathrm{~ms}$, and that of the neutral syllables is $284 \mathrm{~ms}$, with the proportion about 1:0.78. The average duration of the stressed tones in LSD is about $291 \mathrm{~ms}$, and that of the neutral tones is 227 , with the proportion also about 1:0.78.

As noted above, T4 undergoes reduction at the initial position, so that it surfaces as a low falling tone with no rising in the end, but it is still a low tone. Except for this small change, all the other tones stay stable before neutral tone and have not undergone tonal change. The pitch value of the starting point of the neutral tone is 
unanimously in agreement with the ending point of the proceeding stressed tone. The slight difference lies in that of the pattern $\mathrm{T} 2+\mathrm{N}$, with the ending point of $\mathrm{T} 24$ and the starting point of the $\mathrm{N} 3$. As variation within one level is not to be taken seriously, so we can say that the starting point of the neutral tone accords with the ending point of the stressed tone, due to a commonly agreed reason: tonal co-articulation. This phenomenon has been found in many other dialects and is considered as a typical feature of neutral tone in Mandarin Dialects.

As to the ending point of the neutral, it is uniformly low, mostly 2 and sometimes a little bit higher as 3 . This can also be found in many dialects, e.g., Tianjin (WANG, 2002a), Huailai (LV, 2003), to just name a few.

Since the starting point of the neutral tone is caused by co-articulation, which belongs to the field of phonetics, it will not be analyzed within the phonological framework; whereas the end point which has a default value $\mathrm{L}$ will be accounted for by phonological theories later.

The neutral tone in trisyllabic sequences. The following tables show the duration and pitch value of each syllable in trisyllabic sequences $\mathrm{S}+\mathrm{N}+\mathrm{S}$ and $\mathrm{S}+\mathrm{N}+\mathrm{N}$ :

Table 3

Duration and Pitch Value: $T 1+T 0+T x$

\begin{tabular}{|c|c|c|c|c|c|c|}
\hline \multicolumn{2}{|c|}{ Item } & Tone & $1+0+1$ & $1+0+2$ & $1+0+3$ & $1+0+4$ \\
\hline \multirow{3}{*}{$\begin{array}{c}\text { Duration } \\
(\mathrm{ms})\end{array}$} & \multirow{3}{*}{ syllable } & $\mathrm{M}$ & $319+243+264$ & $284+257+279$ & $426+212+391$ & $392+231+525$ \\
\cline { 3 - 7 } & \multirow{2}{*}{ tone } & $\mathrm{F}$ & $279+213+288$ & $190+163+375$ & $246+178+517$ & $247+202+520$ \\
\cline { 2 - 7 } & & $\mathrm{M}$ & $201+203+193$ & $228+190+209$ & $256+166+297$ & $220+187+465$ \\
\cline { 2 - 7 } & $\mathrm{F}$ & $169+179+195$ & $150+121+275$ & $145+142+398$ & $141+174+438$ \\
\hline \multicolumn{2}{|c|}{ Pitch value } & $\mathrm{M}$ & $32+34+42$ & $32+23+34$ & $32+22+23$ & $32+22+12$ \\
\cline { 2 - 7 } & $\mathrm{F}$ & $43+34+31$ & $33+33+43$ & $43+33+34$ & $43+33+22$ \\
\hline
\end{tabular}

Table 4

Duration and Pitch Value: $T 2+T 0+T x$

\begin{tabular}{|c|c|c|c|c|c|c|}
\hline \hline \multicolumn{2}{|c|}{ Item } & Tone & $2+0+1$ & $2+0+2$ & $2+0+3$ & $2+0+4$ \\
\hline \multirow{3}{*}{$\begin{array}{c}\text { Duration } \\
(\mathrm{ms})\end{array}$} & \multirow{2}{*}{ syllable } & $\mathrm{M}$ & $307+234+276$ & $308+272+296$ & $348+259+311$ & $313+185+437$ \\
\cline { 2 - 7 } & & $\mathrm{F}$ & $237+224+247$ & $225+176+304$ & $243+191+457$ & $242+142+360$ \\
\cline { 2 - 7 } & \multirow{2}{*}{ tone } & $\mathrm{M}$ & $201+184+206$ & $209+204+224$ & $221+189+238$ & $226+253+367$ \\
\cline { 2 - 7 } & $\mathrm{F}$ & $157+203+186$ & $178+152+216$ & $178+158+394$ & $195+123+304$ \\
\hline \multicolumn{2}{|c|}{ Pitch value } & $\mathrm{M}$ & $43+44+42$ & $43+32+44$ & $43+32+23$ & $43+32+22$ \\
\cline { 2 - 7 } & $\mathrm{F}$ & $44+44+43$ & $44+43+43$ & $44+32+23$ & $44+32+22$ \\
\hline
\end{tabular}

Table 5

Duration and Pitch Value: $T 3+T 0+T x$

\begin{tabular}{|c|c|c|c|c|c|c|}
\hline \hline \multicolumn{2}{|c|}{ Item } & Tone & $3+0+1$ & $3+0+2$ & $3+0+3$ & $3+0+4$ \\
\hline \multirow{3}{*}{$\begin{array}{c}\text { Duration } \\
(\mathrm{ms})\end{array}$} & \multirow{2}{*}{ syllable } & $\mathrm{M}$ & $308+230+273$ & $312+235+358$ & $321+242+330$ & $362+261+220$ \\
\cline { 2 - 7 } & \multirow{2}{*}{ tone } & $\mathrm{F}$ & $183+207+240$ & $188+211+344$ & $194+184+482$ & $209+174+345$ \\
\cline { 2 - 7 } & & $\mathrm{M}$ & $253+187+208$ & $233+192+256$ & $265+197+251$ & $303+196+181$ \\
\cline { 2 - 7 } & $\mathrm{F}$ & $162+171+177$ & $152+182+263$ & $148+162+387$ & $177+148+298$ \\
\hline \multicolumn{2}{|c|}{ Pitch value } & $\mathrm{M}$ & $34+44+32$ & $34+43+44$ & $34+42+23$ & $34+43+33$ \\
\cline { 2 - 7 } & $\mathrm{F}$ & $34+44+32$ & $34+44+43$ & $33+42+23$ & $33+32+22$ \\
\hline
\end{tabular}


Table 6

Duration and Pitch Value: $T 4+T 0+T x$

\begin{tabular}{|c|c|c|c|c|c|c|}
\hline \multicolumn{3}{|c|}{ Item } & $4+0+1$ & $4+0+2$ & $4+0+3$ & $4+0+4$ \\
\hline \multirow{4}{*}{$\begin{array}{l}\text { Duration } \\
\text { (ms) }\end{array}$} & \multirow{2}{*}{ syllable } & $\mathrm{M}$ & $269+275+290$ & $258+250+307$ & $322+212+418$ & $352+229+312$ \\
\hline & & $\mathrm{F}$ & $218+236+336$ & $201+219+368$ & $197+193+563$ & $253+209+527$ \\
\hline & \multirow{2}{*}{ tone } & M & $221+194+224$ & $213+185+214$ & $214+138+305$ & $232+186+273$ \\
\hline & & $\mathrm{F}$ & $172+183+282$ & $169+173+295$ & $155+141+463$ & $188+165+450$ \\
\hline \multirow{2}{*}{\multicolumn{2}{|c|}{ Pitch value }} & $\mathrm{M}$ & $22+24+32$ & $22+22+44$ & $32+33+23$ & $22+34+43$ \\
\hline & & $\mathrm{F}$ & $33+34+32$ & $33+22+34$ & $33+32+34$ & $32+34+33$ \\
\hline
\end{tabular}

Table 7

Duration and Pitch Value: $T x+T 0+T 0$

\begin{tabular}{|c|c|c|c|c|c|c|}
\hline \multicolumn{2}{|c}{ Item } & Tone & $1+0+0$ & $2+0+0$ & $3+0+0$ & $4+0+0$ \\
\hline \multirow{3}{*}{$\begin{array}{c}\text { Duration } \\
(\mathrm{ms})\end{array}$} & \multirow{2}{*}{ syllable } & $\mathrm{M}$ & $325+241+185$ & $391+208+234$ & $380+272+170$ & $335+300+186$ \\
\cline { 3 - 7 } & \multirow{2}{*}{ tone } & $\mathrm{F}$ & $257+193+324$ & $270+164+318$ & $244+175+303$ & $207+231+381$ \\
\cline { 2 - 7 } & & $\mathrm{M}$ & $277+201+130$ & $269+173+166$ & $260+176+122$ & $247+226+126$ \\
\cline { 2 - 7 } & $\mathrm{F}$ & $201+161+280$ & $207+127+251$ & $214+148+261$ & $172+201+336$ \\
\hline \multicolumn{2}{|c|}{ Pitch value } & $\mathrm{M}$ & $32+21+11$ & $43+32+22$ & $24+44+43$ & $21+23+32$ \\
\cline { 2 - 7 } & $\mathrm{F}$ & $43+33+32$ & $44+33+33$ & $34+44+32$ & $33+33+32$ \\
\hline
\end{tabular}

From the above tables, it is easily seen that the duration of the neutral tone is generally much shorter than that of the stressed tone. And as to the stressed syllables, the final ones tend to have longer duration, which is a widely proved fact generally accounted for by the "pre-boundary lengthening" explanation.

In LSD, the ratio between the duration of the tones of different syllables in $\mathrm{S}+\mathrm{N}+\mathrm{S}$ structure is $1.29: 1: 1.93$. A neutral tone is $77 \%$ as long as the initial syllable but only $52 \%$ as long as the final one. As to the $\mathrm{S}+\mathrm{N}+\mathrm{N}$ pattern, the ratio between the duration of the tones of the different syllables is 1:0.75:0.97. The result is coherent with the previous observation that the neutral tone may have different length of duration according to its different position, and usually the final one is longer.

After the observation of the tonal modifications in the trisyllabic sequences, the following generalizations can be made.

In $\mathrm{S}+\mathrm{N}+\mathrm{S}$ phrases, both the initial and final stressed syllables maintain their original tones, although there are some small changes in pitch value. Just like in disyllabic sequences, the starting point of the neutral tone is always in agreement with the end point of the previous syllable due to tonal co-articulation, while the end point of the neutral tone is determined by the tonal category of the following syllable. Generally the end point of the neutral tone gets $\mathrm{H}$ when followed by a syllable initialized by $\mathrm{H}$ toneme, like T1 and T2, while L before a syllable started with L toneme, like T3 and T4. Exceptions appear when neutral tone comes in-between T2 and T2, two high level tones; in-between T4 and T2, a low level and a high level tone; and in-between T4 and T4, two low level tones, which needs further explanation.

In $\mathrm{S}+\mathrm{N}+\mathrm{N}$ patterns, still the stressed tones remain unchanged, except with slight modification in absolute pitch value. However, the behavior of the two neutral tones appears somewhat complicated. It may introduce two variable explanations. The tonal modification of the $\mathrm{S}+\mathrm{N}+\mathrm{N}$ pattern is presented in the $\mathrm{H}$, $\mathrm{L}$ structure as follows if we only take the end point of the neutral tone into consideration: 
Table 8

Surface Representations of Neutral Tones in $S+N+N$ Phrases

\begin{tabular}{|c|c|c|}
\hline & First N & Final N \\
\hline T1HL & L & L \\
\hline T2HH & L & L \\
\hline T3LH & H & L \\
\hline T4LL & L & L \\
\hline
\end{tabular}

Here it seems the neutral tone behavior in the pattern $\mathrm{S}+\mathrm{N}+\mathrm{N}$ is similar to that of $\mathrm{S}+\mathrm{N}$, with the end point of the neutral tone as default L generally, only with one exception: after the rising tone T3. Phonetically it is easily understood that it is not easy for a rising tone falls sharply, so here the first neutral tone simply acts as an intermediate tone for the transition of the rising tone to a low tone. However, if observed carefully enough, it seems obvious that in $\mathrm{S}+\mathrm{N}+\mathrm{N}$ pattern, the two neutral tones simply have the same performance as the single $\mathrm{N}$ in $\mathrm{S}+\mathrm{N}$ pattern. To be more explicit, the starting point of the first neutral tone and the end point of the second neutral tone are presented as below:

Table 9

Underlying Representations of Neutral Tones in $S+N+N$ Phrases

\begin{tabular}{|c|c|c|}
\hline & First N & Final N \\
\hline T1HL & L & L \\
\hline T2HH & H & L \\
\hline T3LH & H & L \\
\hline T4LL & L & \\
\hline
\end{tabular}

Now it is clearer that the two $\mathrm{Ns}$ in $\mathrm{S}+\mathrm{N}+\mathrm{N}$ pattern simply act as the single $\mathrm{N}$ in $\mathrm{S}+\mathrm{N}$ pattern, with the first $\mathrm{N}$ co-articulating with the preceding stressed tone and the final $\mathrm{N}$ getting default L. So in $\mathrm{S}+\mathrm{N}+\mathrm{N}$, the behavior of the first $\mathrm{N}$ is in phonetic domain just like the starting point of the $\mathrm{N}$ in $\mathrm{S}+\mathrm{N}$ pattern, and only the behavior of the final $\mathrm{N}$ will be accounted for within the phonological theory.

\section{Phonological Analysis}

\section{Underlying Representation of Neutral Tones}

Concerning the tonal inventory of LSD, two features $\mathrm{H}$ and $\mathrm{L}$ are sufficient to distinguish all the underlying tones. Where 1 and 2 are recorded as L, 4 and 5 are recorded as $\mathrm{H}$, but whether 3 belongs to $\mathrm{H}$ or L depends on its surrounding tones as mentioned before. By employing the underlying representation of five tones, and using tonal features $\mathrm{H}$ and $\mathrm{L}$, the pitch values of the neutral tone in disyllabic sequences and patterns of $\mathrm{S}+\mathrm{N}+\mathrm{S}$ and $\mathrm{S}+\mathrm{N}+\mathrm{N}$ of LSD are presented in the following tables:

Table 10

Underlying Representations of Neutral Tones in Disyllabic Phrases

\begin{tabular}{|c|c|}
\hline The stressed tone & The neutral tone \\
\hline (T1) HL & LL \\
\hline (T2) HH & HL \\
\hline (T3) LH & HL \\
\hline (T4) LL & LL \\
\hline
\end{tabular}


Table 11

Underlying Representations of Neutral Tones in $S+N+N$ Phrases

\begin{tabular}{|c|c|}
\hline Patterns of combinations & Pitch values of tones \\
\hline $\mathrm{T} 1+\mathrm{T} 0+\mathrm{T} 0$ & $\mathrm{HL}+\mathrm{L}+\mathrm{L}$ \\
\hline $\mathrm{T} 2+\mathrm{T} 0+\mathrm{T} 0$ & $\mathrm{HH}+\mathrm{H}+\mathrm{L}$ \\
\hline $\mathrm{T} 3+\mathrm{T} 0+\mathrm{T} 0$ & $\mathrm{LH}+\mathrm{H}+\mathrm{L}$ \\
\hline $\mathrm{T} 4+\mathrm{T} 0+\mathrm{T} 0$ & $\mathrm{LL}+\mathrm{L}+\mathrm{L}$ \\
\hline
\end{tabular}

Table 12

Underlying Representations of Neutral Tones in $S+N+S$ Phrases

\begin{tabular}{|c|c|c|c|c|}
\hline $\mathrm{S} 1+\mathrm{N}+\mathrm{S} 2$ & $(\mathrm{~T} 1) \mathrm{HL}$ & $(\mathrm{T} 2) \mathrm{HH}$ & (T3) LH & (T4) LL \\
\hline$(\mathrm{T} 1) \mathrm{HL}$ & $\mathrm{H}$ & $\mathrm{H}$ & $\mathrm{L}$ & $\mathrm{L}$ \\
\hline$(\mathrm{T} 2) \mathrm{HH}$ & $\mathrm{H}$ & $\mathrm{L}$ & $\mathrm{L}$ & $\mathrm{L}$ \\
\hline$(\mathrm{T} 3) \mathrm{LH}$ & $\mathrm{H}$ & $\mathrm{H}$ & $\mathrm{L}$ & $\mathrm{H}$ \\
\hline$(\mathrm{T} 4) \mathrm{LL}$ & $\mathrm{H}$ & $\mathrm{L}$ & $\mathrm{L}$ & \\
\hline
\end{tabular}

From the above table, it is easily seen that the starting point of the neutral tone in $\mathrm{S}+\mathrm{N}$ pattern and that of the first neutral tone in $\mathrm{S}+\mathrm{N}+\mathrm{N}$ pattern agree with the end point of the preceding syllable, which is due to co-articulation and thus a result of phonetic effect; while the end point of the neutral tone in $\mathrm{S}+\mathrm{N}$ pattern and that of the final neutral tone in $\mathrm{S}+\mathrm{N}+\mathrm{N}$ pattern are consistently $\mathrm{L}$, and should be accounted for within the phonological domain.

As in $\mathrm{S}+\mathrm{N}+\mathrm{S}$ pattern, the end point of the neutral tone is generally in accordance with the starting of the following syllable. The deviations from the generalization are marked in boldface.

\section{Optimality Theory}

Optimality Theory (OT hereafter) is a kind of linguistic theory firstly put forward by phonologist Alan Prince and cognitive scientist Paul Smolensky at the beginning of 1990s. OT utilizes constraints and constraint interaction, thus relates input and output and selects the most harmonious form as the surface form.

The theoretical framework of OT can thus be schematically represented below ( $>>$ is read "dominate", indicating a higher status is the constraint ranking):

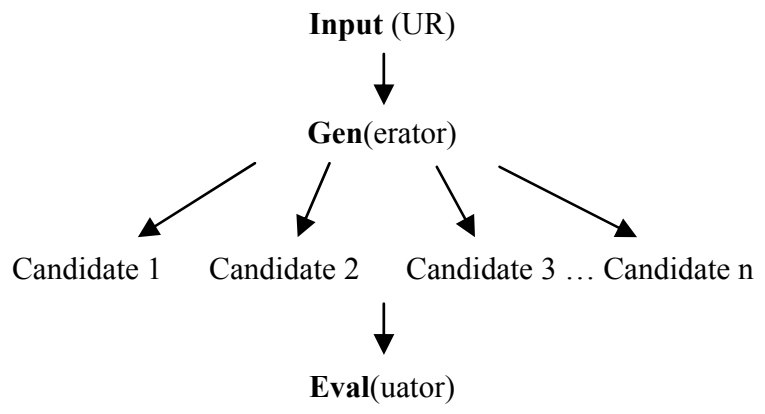

The constraint hierarchy

(Constraint $1>$ Constraint 2

$\ldots>$ Constraint $\mathrm{n}$ )

Optimal output (PR)

Figure 1. Schema of OT grammar. 
OT recognizes two types of constraints: faithfulness constraints and markedness constraints. Each individual constraint evaluates one specific aspect of output markedness or faithfulness. Consequently, the two types of constraints are intrinsically in conflict, and that is where the hierarchy or ranking comes into play. Usually, constraint conflict resulted from incompatible constraint requirement is solved by satisfying the requirement of a higher ranked constraint at the expense of violating the lower one.

\section{OT Analysis of the Neutral Tone in $\mathbf{S}+\mathbf{N}$ and $\mathbf{S}+\mathbf{N}+\mathbf{N}$ Patterns in LSD}

Constraints. (1) Mora-Tone Mapping ( $\mu$-T for short): This constraint requires that morae should and must be linked to single tonal features;

(2) High Neutral Tone Constraint $\left({ }^{*} \mathrm{HN}\right.$ for short): This constraint states that neutral tone cannot have the tonal feature $\mathrm{H}$ in final position.

Ranking of constraints. Since only the end point of the neutral tone in $\mathrm{S}+\mathrm{N}$ pattern and that of the final neutral tone in $\mathrm{S}+\mathrm{N}+\mathrm{N}$ patterns are of phonological concern, and they all get default tonal feature $\mathrm{L}$, the above two constraints do not outrank each other, and only one example of each pattern will be given here.

\section{Evaluation.}

Table 13

$T 1+T 0$

\begin{tabular}{|c|c|c|}
\hline Input: $\mathrm{HL}+\mathrm{N}_{0}$ & $\mu-\mathrm{T}$ & $* \mathrm{HN}$ \\
\hline $\mathrm{HL}+\mathrm{N}_{0}$ & $* !$ & \\
\hline $\mathrm{HL}+\mathrm{L}$ & & $* !$ \\
\hline $\mathrm{HL}+\mathrm{H}$ & & \\
\hline
\end{tabular}

Table 14

$T 1+T 0+T 0$

\begin{tabular}{|c|c|c|}
\hline Input: $\mathrm{HL}+\mathrm{L}+\mathrm{N}_{0}$ & $\mu-\mathrm{T}$ & $* \mathrm{HN}$ \\
\hline $\mathrm{HL}+\mathrm{L}+\mathrm{N}_{0}$ & $* !$ & \\
\hline $\mathrm{HL}+\mathrm{L}+\mathrm{L}$ & & $* !$ \\
\hline
\end{tabular}

\section{OT Analysis of Neutral Tone in $\mathbf{S}+\mathbf{N}+\mathrm{S}$ Pattern}

Constraints. (1) Mora-Tone Mapping ( $\mu$-T for short)

It requires that morae should and must be linked to single tonal features;

(2) Stress-Stability (Str-Stab for short)

In sequences with neutral tones, stressed syllables remain their tones intact as compared with the neutral ones. This is a constraint put forward by Jiao (2004).

(3) IDENT-OO(T-f)

IDENT-OO(T-f) states that tonal feature of the neutral syllable in output form corresponds to the tightly adjacent one carried by the following stressed syllable. This constraint is a development of Correspondence Theory, which maximizes the phonological identity between tonal related output forms.

(4) Consecutive Same Toneme Constraint (*XX.X.XX for short) $(\mathrm{X}=\mathrm{H}$ or L)

Five same tonemes can never appear consecutively together in the output. So the combinations like HH.H.HH and LL.L.LL are banned from surface form. It is another example of OCP. 
(5) High Neutral Tone Constraint (*HN for short)

This constraint states that neutral tone cannot have the tonal feature $\mathrm{H}$.

(6) $\mathrm{H}$ in-between Level Tones Constraint (*LT.H.LT for short)

This constraint states that $\mathrm{H}$ cannot appear in-between level tones. So HH.HHH, LL.HHH, LL.H.LL and HH.H.LL are all violations of it.

Ranking of constraints. Following the previous strategies and procedures in constraint-ranking, the hierarchy of the constraints here is shown as: $\mu-\mathrm{T}$, Str-Stab $>*$ XX.X.XX $>$ *LT.H. LT $>>$ $\operatorname{IDENT}-\mathrm{OO}(\mathrm{T}-\mathrm{f})>>$ HN.

OT evaluation of the neutral tone in $\mathbf{S}+\mathbf{N}+\mathbf{N}$ pattern. Because generally the neutral tones behave alike, here only some examples of the normally behaved patterns together with all the deviations are evaluated.

Table 15

$T 1+T 0+T 1$

\begin{tabular}{|c|c|c|c|c|c|c|}
\hline Input: $\mathrm{HL}+\mathrm{N}_{0}+\mathrm{HL}$ & $\mu-\mathrm{T}$ & Str-Stab & $*$ XX.X.XX & $*$ LT.H.LT & IDENT-OO(T-f) & $* \mathrm{H}_{\mathrm{N}}$ \\
\hline $\mathrm{LL}+\mathrm{L}+\mathrm{HL}$ & & $* !$ & & & $*$ & \\
\hline $\mathrm{HL}+\mathrm{L}+\mathrm{LL}$ & & $* !$ & & & & \\
\hline $\mathrm{HL}+\mathrm{N}_{0}+\mathrm{HL}$ & $* !$ & & & & & \\
\hline $\mathrm{HL}+\mathrm{L}+\mathrm{HL}$ & & & & & & $*$ \\
\hline $\mathrm{HL}+\mathrm{H}+\mathrm{HL}$ & & & & & & $*$ \\
\hline
\end{tabular}

Table 16

$T 1+T 0+T 2$

\begin{tabular}{|c|c|c|c|c|c|c|}
\hline Input: $\mathrm{HL}+\mathrm{N}_{0}+\mathrm{HH}$ & $\mu-\mathrm{T}$ & Str-Stab & $*$ XX.X.XX & *LT.H.LT & IDENT-OO(T-f) & $*$ HN \\
\hline $\mathrm{LL}+\mathrm{L}+\mathrm{HH}$ & & $* !$ & & & $*$ & $*$ \\
\hline $\mathrm{HL}+\mathrm{L}+\mathrm{HL}$ & & $* !$ & & & & $*$ \\
\hline $\mathrm{HL}+\mathrm{N}_{0}+\mathrm{HH}$ & $* !$ & & & & & $*$ \\
\hline $\mathrm{HL}+\mathrm{L}+\mathrm{HH}$ & & & & & & $*$ \\
\hline $\mathrm{F}+\mathrm{HL}+\mathrm{HH}$ & & & & & & $*$ \\
\hline
\end{tabular}

Table 17

$T 1+T 0+T 3$

\begin{tabular}{|c|c|c|c|c|c|c|}
\hline Input: $\mathrm{HL}+\mathrm{N}_{0}+\mathrm{LH}$ & $\mu-\mathrm{T}$ & Str-Stab & $*$ XX.X.XX & *LT.H.LT & IDENT-OO(T-f) & $*$ HN \\
\hline $\mathrm{LL}+\mathrm{L}+\mathrm{LH}$ & & $* !$ & & & & $*$ \\
\hline $\mathrm{HL}+\mathrm{L}+\mathrm{HL}$ & & $* !$ & & & & $*$ \\
\hline $\mathrm{HL}+\mathrm{N}_{0}+\mathrm{LH}$ & $* !$ & & & & $* !$ & $*$ \\
\hline $\mathrm{HL}+\mathrm{H}+\mathrm{LH}$ & & & & & & \\
\hline ( $\mathrm{HL}+\mathrm{L}+\mathrm{LH}$ & & & & & & \\
\hline
\end{tabular}

Table 18

$T 1+T 0+T 4$

\begin{tabular}{|c|c|c|c|c|c|c|}
\hline Input: HL $+\mathrm{N}_{0}+\mathrm{LL}$ & $\mu-\mathrm{T}$ & Str-Stab & $*$ XX.X.XX & *LT.H.LT & IDENT-OO(T-f) & $*$ HN \\
\hline $\mathrm{LL}+\mathrm{L}+\mathrm{LL}$ & & $* !$ & & & & \\
\hline $\mathrm{HL}+\mathrm{L}+\mathrm{HL}$ & & $* !$ & & & & $*$ \\
\hline $\mathrm{HL}+\mathrm{N}_{0}+\mathrm{LL}$ & $* !$ & & & & & $* !$ \\
\hline $\mathrm{HL}+\mathrm{H}+\mathrm{LL}$ & & & & & & $*$ \\
\hline $\mathrm{HL}+\mathrm{L}+\mathrm{LL}$ & & & & & & \\
\hline
\end{tabular}


Table 19

$T 2+T 0+T 2$

\begin{tabular}{|c|c|c|c|c|c|c|}
\hline Input: $\mathrm{HH}+\mathrm{N}_{0}+\mathrm{HH}$ & $\mu-\mathrm{T}$ & Str-Stab & $*$ XX.X.XX & $*$ LT.H.LT & IDENT-OO(T-f) & $*$ HN \\
\hline $\mathrm{HL}+\mathrm{L}+\mathrm{HH}$ & & $* !$ & & & $*$ & $*$ \\
\hline $\mathrm{HH}+\mathrm{L}+\mathrm{HL}$ & & $* !$ & & & & \\
\hline $\mathrm{HH}+\mathrm{N}_{0}+\mathrm{HH}$ & $* !$ & & & & & $*$ \\
\hline $\mathrm{HH}+\mathrm{H}+\mathrm{HH}$ & & & $* !$ & $*$ & & $*$ \\
\hline $\mathrm{HH}+\mathrm{L}+\mathrm{HH}$ & & & & & & $*$ \\
\hline
\end{tabular}

Table 20

$T 4+T 0+T 2$

\begin{tabular}{|c|c|l|c|c|c|c|}
\hline Input: $\mathrm{LL}+\mathrm{N}_{0}+\mathrm{HH}$ & $\mu-\mathrm{T}$ & Str-Stab & ${ }^{* X X . X . X X}$ & ${ }^{*}$ LT.H.LT & IDENT-OO(T-f) & $*$ HN \\
\hline $\mathrm{HL}+\mathrm{L}+\mathrm{HH}$ & & $* !$ & & & $*$ & \\
\hline $\mathrm{LL}+\mathrm{L}+\mathrm{HL}$ & & $* !$ & & & $*$ & \\
\hline $\mathrm{LL}+\mathrm{N}_{0}+\mathrm{HH}$ & $* !$ & & & & & \\
\hline $\mathrm{LL}+\mathrm{H}+\mathrm{HH}$ & & & & $* !$ & & $*$ \\
\hline $\mathrm{LL}+\mathrm{L}+\mathrm{HH}$ & & & & & $*$ & \\
\hline
\end{tabular}

Table 21

$T 4+T 0+T 4$

\begin{tabular}{|c|c|c|c|c|c|c|}
\hline Input: LL + $\mathrm{N}_{0}+\mathrm{LL}$ & $\mu-\mathrm{T}$ & Str-Stab & *XX.X.XX & *LT.H.LT & IDENT-OO(T-f) & *HN.\# \\
\hline $\mathrm{LH}+\mathrm{L}+\mathrm{LL}$ & & $* !$ & & & & \\
\hline $\mathrm{LL}+\mathrm{L}+\mathrm{LH}$ & & $* !$ & & & & \\
\hline $\mathrm{LL}+\mathrm{N}_{0}+\mathrm{LL}$ & $* !$ & & & & & \\
\hline $\mathrm{LL}+\mathrm{L}+\mathrm{LL}$ & & & $* !$ & & & \\
\hline LL $+\mathrm{H}+\mathrm{LL}$ & & & & $*$ & $*$ & $*$ \\
\hline
\end{tabular}

By employing three faithfulness constraints and three markedness constraints, the behavior of the neutral tone in LSD has been explicitly explained.

\section{Conclusion}

Citation tones, neutral tones in disyllabic and trisyllabic sequences are examined in this thesis. Generally viewed, the neutral tone in LSD is determined by both phonetics and phonology. In both disyllabic and trisyllabic phrases, the starting point of the neutral tone is in co-articulation with the ending point of the preceding one, which is in the phonetic domain. While in disyllabic phrases, the end point of the neutral tone gains " $\mathrm{L}$ " as its default value, and this is phonological. In the pattern $\mathrm{S}+\mathrm{N}+\mathrm{S}$ trisyllabic phrases, the end point of the intermediate neutral tone has something to do with the tonal category of the following syllable. Generally speaking, the end point of the neutral tone gets the same value as the starting point of the following stressed tone. This phenomenon is also in the domain of phonology. As in the pattern $\mathrm{S}+\mathrm{N}+\mathrm{N}$, the neutral tone behaves similarly to that of $\mathrm{S}+\mathrm{N}$ pattern, with the starting point of the first neutral tone co-articulating with the end point of the preceding tone, while the end point of the final neutral tone is consistently $\mathrm{L}$.

In the analysis of the neutral tones, phonological theory-Optimality Theory is employed. Six constraints are used, three faithfulness and three markedness. While in dealing with the $\mathrm{S}+\mathrm{N}+\mathrm{S}$ pattern, some uncertainty remains. To account for the same tonal feature of the end point of the neutral tone with the starting 
point of the following stressed tone, another constraint is formulated: ${ }^{*} \mathrm{LNH}$, which states that neutral tone cannot be $\mathrm{L}$ before $\mathrm{H}$. It seems that if so, the underlying representation of neutral tone can be unified as $\mathrm{L}$, and only when it appears before $\mathrm{H}$ it surfaces as $\mathrm{H}$. While the constraint appears to be too language-specific, so the constraint IDENT-OO(T-f), a variation of the constraint IDENT-OO(T) is adopted, since it is more universal.

\section{References}

HOU, J. Y. (2002). Xiandai Hanyu Fangyan Gailun (Outline of modern Chinese dialect). Shanghai: Shanghai Education Press. LI, R. (1985). The grouping of Chinese dialects. Fangyan, 1, 2-5.

LIN, M. C., \& YAN, J. Z. (1980). Beijinghua Qingsheng de Shengxue Xingzhi (Acoustic properties of neutral tones in Beijing Chinese). Fangyan, 3, 168-177.

Luoshan Local Records Compiling Committee. (1987). The record of Luoshan County.

LV, D. L. (2003). An analysis of tones in Huailai dialect (M.A. thesis, Tianjin Normal University, Tianjin).

René, K. (2001). Optimality theory. Cambridge: Cambridge University Press.

SHI, R. J. (1988). Shuo qingsheng (On neutral tones). Yuyin Yanjiu, 14, 98-109.

WANG, J. L. (1995). Youxuanlun (Optimality theory). Linguistics Abroad, 4, 1-4.

WANG, J. L. (2002a). Youxuanlun he Tianjinhua de Liandubiandiao ji Qingsheng (An optimality theoretic analysis of neutral tone and tone Sandhi in Tianjin dialect). Zhongguo Yuwen, 289, 363-372.

WANG, J. L. (2002b). Sanzhongfangyan Qingsheng de Youxuanlun Fenxi (An optimality theoretic analysis of neutral tones in three dialects). Linguistic Sciences, 1, 78-85.

XU, J. (2008). Tone and tone Sandhi of Luoshan dialect. Beijing: PCC.

Yip, M. (2002). Tone. Cambridge: Cambridge University Press.

ZHAN, B. H. (1991). Hanyu Fangyan yu Fangyan Diaocha (Chinese dialects and dialect survey). Wuhan: Hubei Education Publisher. 